\title{
Fleißig, zuckergierig und nützlich - die Hefe
} Ambitious, Sugar Consuming and Beneficial - Yeast

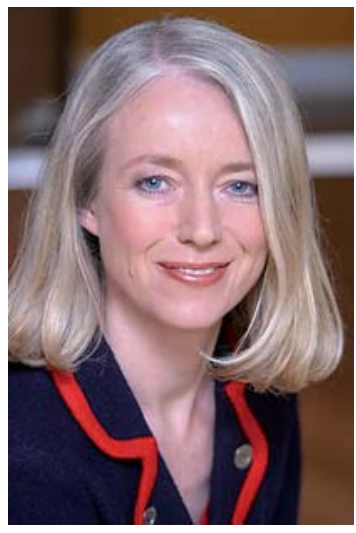

Prof. Dr. Christiane Bayerl
Wer träumt nicht davon, dass die Früchte seiner Arbeit aufgehen wie ein Hefeteig! So ist es den beiden Autoren der mykologischen Fortbildungsserie in der Aktuellen Dermatologie ergangen. Sie haben zu Recht viel Lob geerntet. Die mykologische Serie setzt sich noch fort bis zu den Schimmelpilzen.

Es drängt mich aber, etwas zur Entschuldigung der „Pilze“, konkreter der Hefe als Nahrungsmittel beizutragen. Der überwiegend nützliche Sprosspilz produziert unter Sauerstoffausschluss zur Energieproduktion aus Zucker Alkohol über den Prozess der Gärung. Die einzellige Hefe ist der „Dynamiker“ in der Produktion von Wein, Bier und Brot. Saccharomyceticeae werden in der Bierproduktion ober- oder untergärig eingesetzt. Hochgärige Bierhefen produzieren besonders viel Alkohol. Weinhefen sind besonders gepflegt, Reinhefen sind speziell selektiert - je nachdem, ob sie bei der Produktion von Weiß-, Schaum- oder Rotweinen mitwirken sollen. Die Bäckerhefe braucht leichte Wärme, Luft, Wasser, Kohlenhydrate und Zucker in richtiger Menge. Fett und Salz dagegen stören das Aufgehen des Teiges. Zudem gibt es Hefen als Brotaufstrich. Marmite war das erste kommerzielle Produkt und existiert seit 1902. Zudem sind Vitamine in Hefen zu finden, in der Bierhefe sind es z.B. die Vitamine B1, B2 und B6.

Louis Pasteur, französischer Chemiker und Biologe (1822-1895), hat die Hefen handzahm gemacht. Potenziell krankheitserregende Mikroorganismen in einem flüssigen Lebensmittel wie Milch werden beim Pasteurisieren durch Erhitzung bei $60-85^{\circ} \mathrm{C}$ zerstört, während gleichzeitig Vitamine, Nährstoffe und Geschmacksstoffe größtenteils erhalten bleiben. Nach der Pasteurisierung sind enthaltene Mikroorganismen noch keimfähig. Entsprechend bleiben die Lebensmittel nur beschränkt haltbar. Nur H-Milch (haltbare Milch) wird ultrahocherhitzt bei $135-150^{\circ} \mathrm{C}$, sodass alle vermehrungs- fähigen Keime abgetötet sind, aber auch Milchbestandteile zerstört werden.

Über Probiotika in der Allergieprävention, insbesondere der Säuglingsernährung, hat die Aktuelle Dermatologie bereits berichtet (Treudler R, Simon JC, Ausgabe 12/2007; 33: 466-471 und Bayerl C, Winckelmann U, Ausgabe 4/2007; 33: 126-130 und Müller HS, Ausgabe 5/2011; 37: 176-179). Bei Darmerkrankungen wird über Probiotika positiv berichtet. Dagegen scheinen sich bei Morbus Crohn zumindest prozessierter Käse und Hefen ungünstig auf die Stuhlfrequenzen auszuwirken. Eine entsprechende Diät reduzierte deutlich die Schmerzen und erhöhte das Wohlbefinden [1]. Andererseits finden sich neue Berichte zu Hefe und Thioredoxin-angereicherten Extrakten, die die Allergenität von Nahrungsmitteln reduzieren könnten. Thioredoxin katalysiert die Reduktion von Disulfid-Bindungen in Proteinen über ein NADPH-abhängiges Thioredoxin-Reduktase-System. Thioredoxin-angereicherte Extrakte wurden aus dem essbaren Hefepilz Saccharomyces cerevisiae gewonnen. Eine Reduktion von Disulfid-Bindungen soll das allergene Potenzial einiger Nahrungsmittelallergene senken. Das wäre ein interessanter Ansatz, um Nahrungsmittelallergien zu modulieren [2].

Ihre

Christiane Bayerl

\section{Literatur}

1 Bentz S, Hausmann M, Piberger $H$ et al. Clinical relevance of IgG antibodies against food antigens in Crohn's disease: a double-blind cross-over diet intervention study. Digestion 2010; 81: 252 - 264

2 Taketani Y, Kinugasa K, Furukawa S et al. Yeast thioredoxin-enriched extracts for mitigating the allergenicity of foods. Biosci Biotechnol Biochem 2011; 75: $1872-1879$
Bibliografie

DOI http://dx.doi.org/

$10.1055 / \mathrm{s}-0030-1257094$

Akt Dermatol 2011; 37; 433

(c) Georg Thieme Verlag KG .

Stuttgart · New York

ISSN 0340-2541

Korrespondenzadresse

Prof. Dr. med. Christiane BayerI

Klinik für Dermatologie

und Allergologie

HSK, Wilhelm-Fresenius-Klinik GmbH

Städtisches Klinikum Wiesbaden

Lehrkrankenhaus der Univ. Mainz

Aukammallee 39

65191 Wiesbaden

christiane.bayerl@

hsk-wiesbaden.de 